\section{Ovchinnikov defended}

SIR - We cannot accept the comments of Vera Rich (Nature 335, 107; 1988) about the research project on the perfluorocarbon blood substitute, Perftoran, an analogue of Fluosol-DA, Japan, undertaken at the Institute of Biophysics of the USSR Academy of Sciences. We believe that they cast undeserved suspicion on the memory of the late Professor Yuri Ovchinnikov.

In 1987, Professor Genrikh Ivanitskii, the former head of the Perftoran project, initiated in the Soviet media a campaign intended to show him as an innovator suffering for his attempts to introduce a miracle blood substitute into clinical practice, and to inspire the idea that Ovchinnikov impeded the project.

In reality, the Perftoran blood substitute suitable for use in humans never existed. Such was the conclusion of the commission of the USSR Academy of Sciences which scrupulously considered the matter and recently published a summary of the work done in Vestnik Akademii Nauk SSR (Academy Herald, Russian) issue 6, pp. 57-64 (1989).

Ovchinnikov, who was vice-president of the USSR Academy of Sciences responsible for biological research, did his best to provide clinicians with effective medical products. In her comments, Vera Rich simply repeated the version promulgated by Ivanitskii.

ALEXANDERA. BAEV VADIMT. IVANOV

\section{Shemyakin Institute of \\ Bioorganic Chemistry, \\ Academy of Sciences of the USSR, 117901 Moscow, USSR}

\section{FDA pressure?}

SrR-I note with interest in the review article on "Chemical asymmetric synthesis" (Nature 342, 631-6; 1989) the observation that "pressure from regulatory agencies" is being exerted to "synthesize all potential new drugs as single enantiomers". I do not know which regulatory bodies the authors have in mind, but the US Food and Drug Administration (FDA) cannot be among them.

About 25 years ago, when one of many controversies erupted about the safety of marketed drugs, I noted that one of those drugs, possessing one chiral centre, was marketed as a racemic modification. Newly arrived at the FDA, I learned early that someone at my level of reviewing chemist could never hope to persuade a pharmaceutical company to do something against its wishes, if to do so would cost it money or set back its approval. I recommended internally, therefore, that the company be requested to resolve the compound and subject its enantiomers to tests that might show that one of the enantiomers was unnecessary or superior to the other. As a goad to accomplishing this objective, I also recommended (as a non-lawyer) that the FDA could invoke certain provisions of the Food, Drug, and Cosmetic Act, as amended, that deem a drug to be adulterated [Section 505]: “A drug ... . shall be deemed to be adulterated $-\ldots$ if it has been prepared . . . whereby it may have been rendered injurious to health"; [(a) (2) (A)] and "If . . . any substance has been mixed ... therewith so as to reduce its quality or strength [(d) (1)]".

Although these provisions could not have been written into law with stereochemical considerations in mind, I believed them to be applicable to the question of safety of drugs with respect to the presence of an unwanted (and perhaps unnecessary) enantiomer as an adulterant.

This effort was prevented by the chief chemist of the FDA's Bureau of Drugs, who, as an inorganic chemist, could not appreciate the argument of organic chemistry, as well as being fearful of antagonizing the pharmaceutical industry. During my career in the FDA from 1963 to 1983, I know of no example of the FDA intervening to require that a company demonstrate the safety or efficacy of one enantiomer over its non-superposable mirror image or over the corresponding racemic modification. Nor have I heard subsequently of any such action.

Not only would the FDA not make any such objection, it was unable to recognize the existence of compounds with multiple chiral centres and was therefore hoodwinked into accepting at least one drug that is capable of existing as one of four diastereoisomeric pairs or mixtures thereof (see, for example, Akineton, generic name: biperiden)

PO Box 16057 ,

Burton L. Appleton

Alexandria, Virginia 22302, USA

\section{A Pauling biography}

SIR-The review by R. J. P. Williams of Serafini's Pauling biography (Nature 342, 135 ; 1989) mostly displays Williams's musings as to what makes Pauling tick. While Williams is, of course, entitled to his opinions, our image of Linus Pauling is far more positive and we are especially incensed by the biographer's view of Paulings motivations, such as a need for tension and quarrels. We believe that Pauling was and is simply interested in everything accessible to his insights. He also fights for what he feels to be true and just. Indeed, we certainly subscribe to Williams's penultimate sentence: "Pauling . . . was for quite some time just the best of us". And we wonder whether we have yet seen the end of his great successes.
Williams also fails to address the quality of the biography itself; it is awful. For example, periods of time are hopelessly mixed up again and again and the book is utterly slipshod otherwise (typographical errors, errors of fact and misconceptions abound: for example, column should be Coulomb and invariant [and] proportional should be inversely proportional, page 77; Ostwald should be Oswald Avery, page 152, Lorenson should be Lauritsen page 141). The book is excessively repetitive and the same interview quotations also often appear several times. We have no recollection of many occurrences Serafini relates (although one or both of us were at Caltech at the time), such as heated and loud political discussions between Pauling and Millikan in the halls of Gates and Crellin - we do not even recall ever seeing Millikan on these premises. We view as unfounded the allegations that Pauling was unsympathetic towards organic chemistry or the humanities division. And so on. So, as to both the facts and to the flavour of things in the Pauling days, we fear that Serafini's biography is totally unreliable.

JÜRG WASER

6120 Terryhill Drive,

La Jolla, California 92037, USA

VERNER SCHOMAKER

California Institute of Technology,

Pasadena, California 91125, USA

\section{Fetus research}

SIR-In a recent Commentary (Nature $342,469 ; 1989)$, reference was made to the report of the Polkinghorne Committee on the use of fetuses and fetal material for research. Research on living intact aborted fetuses is apparently forbidden, but the reported criteria for death are absence of heartbeat or of spontaneous respiration. (The 'or' may be significant). Fetal heartbeat may be difficult to detect, and capability for spontaneous respiration is rarely established until the seventh month of gestation, the legal limit for abortion in the United Kingdom anyway. Experimentation on a spontaneously breathing fetus would then in law constitute infanticide.

Far from presenting 'strict guidelines', the Polkinghorne criteria are therefore the minimal precautions to be observed by an experimenter to avoid not just controversy but also the possibility of criminal prosecution. Had the concern been to avoid the possibility of distress to a sentient experimental subject, the appropriate guideline would be the definitive and confirmed cessation of activity in the central nervous system, as is the general requirement on human subjects. A. J. McEvoY

Institut de Chimie Physique,

EPFL-Ecublens,

CH-1015 Lausanne, Switzerland 